Article

\title{
Indigenous Knowledge and Acceptability of Treated Effluent in Agriculture
}

\author{
Andrew Emmanuel Okem ${ }^{1, *}$ and Alfred Oduor Odindo ${ }^{2}$ \\ 1 School of Life Sciences, University of KwaZulu Natal, Durban 4000, South Africa \\ 2 School of Agricultural, Earth and Environmental Sciences, University of KwaZulu Natal, \\ Pietermaritzburg 3209, South Africa; odindoa@ukzn.ac.za \\ * Correspondence: okem@ukzn.ac.za
}

Received: 17 September 2020; Accepted: 19 October 2020; Published: 9 November 2020

\begin{abstract}
The twin challenges of lack of access to improved sanitation and food insecurity remain critical, particularly in the global south. With cognizance of the nutrient potential of human excreta, there has been increasing interest in linking sanitation innovations with agriculture by using nutrients recovered from human excreta for crop production, thus, closing the nutrient loop. While studies and field trials have explored and validated the technical feasibility of reusing nutrients recovered from human excreta in agriculture, there is still limited knowledge of its social acceptability. This study examined whether indigenous knowledge can be leveraged to increase the acceptability of human-excreta-derived plant nutrient sources such as treated effluent in agriculture. A qualitative research design comprising seven focus group interviews (five in rural areas and two in peri-urban areas) was conducted in KwaZulu Natal, South Africa. Findings from the focus groups reveal a willingness to grow and consume food using treated effluent. Additionally, participants made references to indigenous practices that encourage recycling and reuse of human excreta. Given the potential to simultaneously address issues of food insecurity and sanitation that characterize many peri-urban and rural areas in South Africa, we recommend further studies in this area.
\end{abstract}

Keywords: agriculture; effluent; food security; indigenous knowledge; sanitation

\section{Introduction}

Ongoing sanitation backlog (defined as the number of people without access to improved sanitation) and food insecurity are among key development challenges, particularly in the global south. In recent years, there has been increasing recognition of the linkage between sanitation and food security [1-6]. This has resulted in calls for bridging the nutrient loop. This paper draws on the experience of a project titled "Integrating Agriculture in Designing Low-Cost Sanitation Technologies in Social Housing Schemes". The project aims to provide design data for the agricultural use of treated wastewater from a Decentralized Wastewater Treatment System (DEWATS) plant. Treated wastewater refers to "wastewater that has been processed through a wastewater treatment plant and been subjected to one or more physical, chemical, and biological processes to reduce its pollution or health hazard" [7]. The DEWATS plant usually caters for settlements from 20 to 2000 households. The wastewater treatment plant consists of a biogas/settler pre-treatment step, an anaerobic baffled reactor, two anaerobic filter chambers and effluent polishing in a constructed wetland.

The waste from households is passed through the anaerobic baffled reactor and filtered. The ABR effluent then passes through the constructed wetland and the end product is a clear liquid rich in plant nutrients (nitrogen and phosphorus).

The treated effluent poses a challenge concerning disposal because it contains high concentrations of nitrogen $(\mathrm{N})$ and phosphorus $(\mathrm{P})$, which do not meet regulatory standards for discharge and can 
contaminate surface and groundwater bodies [8]. However, using this effluent in agriculture could provide an innovative way of disposal in a manner that is environmentally safe and beneficial to society. The effluent can be used for gardens in both horticulture and hydroponic production, as well as for cereal crops, such as maize.

As part of the project, a microbial risk assessment was done to ensure the safe use of human-excreta-derived materials in agriculture while protecting workers using the World Health Organization (WHO) Sanitation Safety Plans (SSP) approach [8]. The risk assessment covered all sanitation steps, from the collection of human excreta to the consumption of crops produced from these products. The scoring method is adapted from the semi-quantitative risk assessment matrix of the World Health Organization [9]. The South African Occupational Health and Safety Act of 1993 [10] requires that a safe environment without health risks is provided to workers. The risk assessment sheet did not show high-risk hazards; however, recommendations were made on the possible control measures that can be implemented for farmers, workers and consumers. These include public awareness programs and training for the proper use of urine-diverting dry toilets to avoid contamination from faecal matter, training programs for the operations and maintenance teams, including urine collectors, site and laboratory inductions for people with access to the site, and, during the implementation stage, engagement with commercial farmers so that the local communities can learn from them. In addition, raising awareness on hygienic practices and post-harvest handling of crops produced with HEDMs and wastewater was recommended. Practices include using submerged irrigation systems for the application of treated wastewater, ensuring an interval between the last irrigation event and harvesting, and careful crop selection-planting crops that are not eaten raw and whose edible parts are covered in protective tissue, such as banana peel, maize husk, or bean pod [8]. Results from field trials showed that the performance of banana/taro intercrop with respect to growth, and yield was comparable with the control, which was chemical commercial fertilizer. Further research is needed to develop models that can be used to calculate the land area needed to absorb effluent from a DEWATS plant with a specific capacity.

\subsection{An Overview of the Current State of Global Sanitation}

Over the years, access to improved sanitation has been recognized as a global challenge. According to recent estimates, about one-third (2.4 billion people) of the global population do not have access to improved sanitation [11]. The World Health Organization WHO/ the United Nations Children's Fund Joint Monitoring Programme for Water Supply [12] defines improved sanitation as "sanitation facilities are those designed to hygienically separate excreta from human contact". According to the World Health Organization's Key Facts on Sanitation [11], "2.0 billion people still do not have basic sanitation facilities such as toilets or latrines." The prevalence of sanitation backlog varies significantly across different regions, with most (90\%) of the population without access to improved sanitation residing in South Asia, Sub-Saharan Africa, East Asia, and the Pacific where nearly one billion (40\%), 706 million (30\%), and 520 million (22\%) of the population, respectively, still lack access to improved sanitation [11]. In addition to this regional disparity, there is also a disparity between rural and urban areas in terms of access to improved sanitation. Rural areas are often characterized by unimproved pit latrines and open defecation [13]. Ritchie [14] indicate that the proportion of the population resorting to open defecation is below $20 \%$ in urban areas, whereas it ranges between below $20 \%$ and $90 \%$ in rural areas.

Rapid urbanization brings along several challenges related to water quality, environmental degradation, and health risks. This is particularly true for low-income countries typified by rapid population growth in peri-urban areas that are often unserved or have poor sanitation facilities. In urban areas, about two billion people use "toilets connected to septic tanks that are not safely emptied or use other systems that discharge raw sewage into open drains or surface waters" [11]. In the global south, "62 percent of sewage and fecal sludge is unsafely managed somewhere along the sanitation service chain" [15]. Run-off and leaching from open defecation and poorly maintained sanitation 
facilities in these areas pollute surface water and groundwater [16]. A study commissioned by the Water Research Commission found sewage contaminants from commercial, industrial, and residential areas in uMngeni River [17].

Lack of access to improved sanitation has health implications for communities [18]. Poor people, particularly children under five years, bear a higher burden of the health impacts of poor sanitation [19]. According to the Bill and Melinda Gates Foundation [18], faecal contamination of drinking water is a major contributor to diarrhoea, which kills millions of children every year. In middle-income countries such as South Africa, addressing sanitation backlog remains a persistent challenge.

\subsection{The Sanitation Scenario in South Africa}

The use of the toilet as a mode of sanitation is a modern reality in Southern African. According to Haarhoff et al. [20], there are no records that validate the existence of toilets in pre-colonial Southern Africa. Among the Zulu nation, for instance, low population densities, civil strife, and frequent mobility due to pastoral livelihood were factors that contributed to the non-existence of toilet structures. In pre-colonial South Africa, human excreta were simply buried in a shallow hole dug for defecation [21]. Such a practice did not result in any significant relationship with human excreta. The arrival of colonial powers, coupled with increasing urbanization, encouraged the practice of building solid toilet structures [21].

Since the end of the apartheid regime, despite a relative improvement in the access to sanitation facilities, many households are still without adequate access to improved sanitation. The 2017 General Household Survey by Statistics of South Africa [22] shows that households with access to improved sanitation increased from about $62 \%$ in 2002 to nearly $82 \%$ in 2017 . However, many households had no access to sanitation facilities or relied on the bucket toilet system, although the percentage in these categories declined from nearly 13\% to nearly 3\% during the same period (Statistics South Africa, 2017). A community survey conducted by Statistics South Africa [22] found that sanitation backlog was $12.7 \%$ in metropolitan municipalities compared to $50.6 \%$ in rural municipalities. To address ongoing sanitation backlog, exploring innovative strategies, such as linking sanitation systems in housing schemes to agriculture, has gained prominence in recent years.

\subsection{The Linkage between Sanitation and Food Security}

There have been proposals for the integration of agriculture into the design of sanitation facilities in recent years [3,19]. This view is often linked to the idea of ecological sanitation (EcoSan). According to Langergraber and Muellegger [23], EcoSan is "a sustainable, closed-loop system, which sanitation and agriculture. The underlying aim is to close (local) nutrient and water cycles with as less expenditure on material and energy as possible to contribute to sustainable development." This approach is underpinned by a paradigm shift towards seeing human excreta as a resource and calls for exploring new ways to reuse it instead of it being discarded as waste.

Proponents of the reuse of human excreta in agriculture argue that they are a source of macronutrients, including nitrogen $(\mathrm{N})$, phosphorus $(\mathrm{P})$, and potassium $(\mathrm{K})$ [23]. In addition, $\mathrm{P}$ is a finite resource that could be exhausted in the next 50-100 years [23]. According to Langergraber and Muellegger [23], "Some researchers assume that within a century, the severity of the phosphorus crisis will result in increasing food prices, food shortages, and geopolitical rifts." Although continuous access to phosphate is critical to global food security, this has not been given the requisite recognition in studies around food security. In addition, patterns of phosphorus extraction give the impression that $\mathrm{P}$ is an infinite resource [23,24]. Ironically, Africa, which is the major exporter of phosphate rocks, has been the most food-insecure continent.

To avert future crises related to phosphate depletion, exploration of its alternative sources is quintessential for future global food security. Human excreta have been known to be a valuable source of P. Per annum urine produced by one person "is sufficient to fertilize $300-400 \mathrm{~m}^{2}$ of crop to a level of about 50-100 kg N/ha" [25]. A study in Niger revealed "that the annual amount of plant nutrients in 
the excreta (urine + faeces) from one family is roughly equal to the quantity in one $50 \mathrm{~kg}$ bag of urea and one $50 \mathrm{~kg}$ bag of NPK" [25]. The benefit of using human excreta in agriculture and the associated benefit of reducing environmental degradation has been documented. Studies have documented traditional practices involving reuse of human faecal matter as fertilizers in countries such as Japan, China, Pakistan, Kenya, Haiti, and Sweden [13,26,27].

Approaches to faecal matter treatment comprise mainly centralized systems that are often characterized by huge capital investment, high maintenance costs, and excessive wastage of water [28]. South Africa is a water-scarce country [29], and projections indicate that the impact of climate change will worsen water scarcity [30]. In this context, it is imperative to not only explore dry sanitation options, but also the recycling of nutrients and water from wet sanitation systems. However, there are barriers to the adoption of human excreta as fertilizer in agriculture.

\subsection{Barriers to the Acceptance of Human Excreta Reuse in Agriculture}

Despite the benefits of reusing human excreta in agriculture, the design of sanitation systems has largely ignored incorporating the harvest of human excreta for agricultural purpose [2,24,31]. Around the world, most sanitation systems are underpinned by two main conventional sanitation systems: "drop and forget' or "flush and forget" [32]. These approaches are informed by the notion that human excreta are repulsive, have an unpleasant smell, and are a harbinger of germs and disease $[19,31,33]$. Consequently, sanitation technologies have been seldom designed for harvesting and reusing human excreta.

Although human excreta have beneficial use in agriculture, social acceptance continues to be considered as a key barrier to their adoption. Studies on attitudes and perceptions of resusing human excreta in agriculture reveal that they differ across genders, education, and experience $[19,31,33,34]$. Investigating the perceptions of farmers about the reuse of excreta for peri-urban agriculture in Southern Ghana, Nimoh et al. [34] found that a majority (more than 50\%) of respondents agreed that human excreta are a resource (not a waste) that can be used as a fertilizer. However, men, older persons, and those who lacked formal education or with less experience in the subject matter were more likely to have negative perceptions of excreta reuse compared to their counterparts (women, younger persons, and those with formal education or more experience in agriculture).

Wilde et al. [35] examined public acceptance of nitrified urine fertilizer in Msunduzi Municipality in South Africa. They found that attitudes were generally "much more positive towards the use of nitrified urine fertilizer than raw urine as a soil amendment." Younger respondents and those who resided in rural parts of the municipality were "most receptive to the use of nitrified urine fertilizer" compared to their older and urban counterparts. Unlike previous studies, which advanced religion and culture as underpinning factors for the acceptability of the use of nitrified urine fertilizer [3,33,36,37], the study by Wilde et al. [35] found that respondents distrusted the technology involved in the treatment process. The authors, therefore, concur with the view that "behavior towards sanitation and excrement is a complex interaction between individual and societal norms and is often not based on scientific logic or knowledge" [35].

Another study by Roxburgh [38] on the public acceptability of the use of "human-excreta-derived fertilizer" (HEDF) among peri-urban subsistence farmers in Blantyre, Malawi found that knowledge (in terms of having heard of HEDF or seeing a sample thereof) was a key factor in the acceptability by farmers $(96 \%)$ who expressed their willingness to buy crops (e.g., maize) produced through the use of HEDF [38].

Studies on the reuse of urine in agriculture identify three barriers: lack of knowledge about its value in agriculture, traditional and religious barriers, and smell $[23,33,34,39,40]$. Concerns of the health risks associated with using human excreta in agriculture are also cited as a barrier [33,34,40]. According to Roma et al. [40], concerns about micro-pollutants, hormones, pathogens, and pharmaceuticals are barriers to the reuse of urine in agriculture in both low- and high-income countries. The study noted that the smell of urine is often linked to the presence of pathogens, which makes people wary of using 
it in agriculture [40]. A majority (81\%) of respondents in the study by Nimoh et al. [34] agreed that "handling human excreta can pose great health risk." In a study by Mariwah and Drangert [28], it was noted that $97 \%$ of the participants were of the view that human excreta possess health risks. Another concern in South Africa is about the possible presence of menstrual blood in urine and the transmission of HIV/AIDS through urine [36].

Based on the above, harnessing the agricultural potential of human excreta requires a paradigm shift both in the design of sanitation facilities and attitudes towards human excreta. Although perceptions and acceptability of human excreta vary across the studies presented above, there is mixed evidence of its acceptance across the studies. In this study, we investigate whether indigenous knowledge and practices are barriers/enablers of the adoption of human excreta in agriculture through a case study approach.

\subsection{Understanding the Indigenous Knowledge System}

Indigenous knowledge refers to knowledge that "is unique to a given culture that has been acquired through the accumulation of years of experiences by local people and is passed on from generation to generation" [41]. Indigenous knowledge is orally manifested in "community ceremonies and rituals, namely, story-telling, proverbs, folktales, recitation, demonstration, sport, epic, poetry, reasoning, riddles, praise, songs, word games, puzzles, tongue-twisters, dance, music, and other education-centered activities" [42]. Indigenous knowledge, according to this view, is transmitted by oral tradition, which characterizes traditional life. This knowledge is acquired experientially [41-43]. Indigenous knowledge is generated at the local level to address socio-cultural issues relevant for improved livelihood [44]. Indigenous knowledge is therefore context-specific since the ways of knowing are influenced by contextual factors. However, the relevance of such knowledge is not limited to the community but has practical applications to other communities.

Although indigenous knowledge systems (IKS) predate modern scientific knowledge [44], and are an important element of agriculture, they may be "open to outside influences to meet new environmental demands" [41]. The intensification of globalization is one of the important phenomena of the 20th century and has often undermined indigenous knowledge systems. Globalization is defined as the "global spread and sharing of ideas, cultures, and economic links across the world" [41]. Mankiw [45] refers to this phenomenon as the growing integration of global economies. Through this integration, globalization leads towards the breakdown of cultural, religious, economic, and national borders to create a single integrated system. The implication of this is that local cultural values, beliefs, religion, and ways of knowing are often neglected in favor of those of Western cultures [43].

Globalization has played a significant role in undermining African ways of knowing [43,46,47]. The reality of the global era is that the Western paradigm is presented as the only valid source of knowledge at the expense of other epistemologies. Through this construction, Africans are presented as backwards and devoid of the ability to produce systematic knowledge. This way of thinking is prevalent "in the predominantly Western-oriented academic circles and investigations, [where] the African voice is either sidelined or suppressed because indigenous knowledge and methods are often ignored or not taken seriously" [42]. The approach has resulted in the omission of the contributions of African indigenous knowledge to civilization [48]. However, as Owusu-Ansah and Mji [42] argue, Africa has made significant contributions to civilization. Similarly, there is robust evidence that the non-inclusion of people's knowledge in development intervention often leads to policy failure [49].

Increasingly, the relevance of indigenous knowledge systems to present African and global challenges has been recognized. Against this backdrop, indigenous knowledge has been applied in healthcare [41,46,49,50], agricultural practices [51,52], water and sanitation [21], and climate change [43,53-55]. In this study, we examine if there is/are indigenous knowledge/practices in the study area that could hinder/enable the adoption of the use of human excreta in agriculture. 


\section{Materials and Methods}

This study used the interpretivist paradigm within the broader framework of Afrocentric research. Research in the interpretivist paradigm is "distanced from conventional positivist assumptions, not driven by the objective of hypothesis testing. Rather, the goal is to understand the phenomenon under study" [56]. Afrocentricity, according to Mkabela [57], "locates research from an African viewpoint and creates Africa's intellectual perspective." It emphasizes respect for elders and research participants. Furthermore, the Afrocentric paradigm recognizes the existence of multiple perspectives and encourages local views in answering research questions. The Afrocentric paradigm provides opportunities for "new insights and dimensions in the understanding of African indigenous culture in a multicultural context" [57].

In line with the Afrocentric paradigm, primary data were collected through seven focus group discussions (FGDs). Two of the FGDs were in peri-urban areas, while five were in rural areas of KwaZulu Natal. According to Statistics South Africa's 2016 Community Survey [58], 23\% of households involved in agricultural activities were from KwaZulu Natal. The province is characterized by both large- and small-scale commercial agriculture as well as subsistence agriculture. The choice of the locations was to understand whether perceptions about the use of DEWATS effluent in agriculture are influenced by the rural-urban divide. Each FGD comprised a minimum of five participants, with a maximum of nine participants in the largest group. The participants were purposively selected because of their engagement in agricultural activities. Participants in the study comprised a mix of both small-scale commercial farmers and subsistence farmers. In total, there were 48 participants in all focus groups, and they were predominantly female $(\mathrm{N}=39)$. The overrepresentation of women in the sample could be attributed to our use of purposive sampling. It could also be seen as a reflection of the overrepresentation of women in the agricultural sector in Sub-Saharan Africa, "where women produce up to $80 \%$ of foodstuffs for household consumption and sale in local markets" [59]. The youngest participant in the focus group discussion was 19 years, while the oldest was 77 years.

At the beginning of each FGD, we provided an overview of the aim of the FGDs, explained the DEWATS concept, and how it is linked to agriculture. The explanation was aided with pictures of the DEWATS plant and its integration with agriculture. During the introduction, we ensured an objective presentation of the DEWATS to avoid biasing participants' responses. After the introduction, participants were invited to ask questions on issues that required clarifications. Further discussions only commenced once all participants confirmed that they had a clear understanding of the project. We facilitated the FGDs and were guided by a list of pre-prepared questions, asked follow up questions to clarify comments, and elicited inputs from all participants. All FGDs were audio-recorded after obtaining the permission of the research participants. The recorded discussions were transcribed and coded thematically using NVivo version 11 . NVivo is a qualitative data analysis software owned by QSR International based in Melbourne, Australia. In this study, the software was used to organize texts into related themes. Excerpts related to the key thematic areas were extracted and shown in Table 1. In the remaining part of this report, we present findings from the primary research. 
Table 1. Key thematic findings from focus group discussions and related excerpts.

\begin{tabular}{ll}
\hline \multicolumn{1}{c}{ Key Themes } & \multicolumn{1}{c}{ Illustrative Excerpts from FGDs } \\
\hline & "At the end of the day, we have to accept this kind of thing. \\
I have been taught that I can use greywater on my farm. \\
I have used it and it works" (FGD_rural area). \\
"Yes, we can. If it is something that works, we can use it. \\
$\begin{array}{l}\text { Willingness to use treated sanitation effluent } \\
\text { in agriculture }\end{array}$ & We have problems with water here so we can use it" \\
& (FGD_rural area). \\
"Yes, we will use it because we know that they are not \\
coming straight from the toilet. They will be treated first. \\
We will know in our hearts where it is coming from, but we \\
will use it since it will be treated" (FGD_peri-urban).
\end{tabular}

"I will eat the food grown in that way. Maybe we might be already eating this because the cabbage we buy from the shop, we do not know what they are grown from, but we eat that food" (FGD_Peri-urban).

"The amaranth that we buy, those people that are selling it, where are they picking it? Those selling in Durban pick them at the dumpsite and people buy it from them. People won't go to pick these themselves, but they will buy

Willingness to consume food grown with treated sanitation effluent it knowing very well where it is picked from"

(FGD_Peri-urban).

"Yes, I can eat it. For example, when I plant cabbage and it becomes infected, we take these DDT chemicals and we spray. We don't know what these sprays contain but we still use it. I don't think this water is worse than those chemicals that I use" (FGD_rural area).

"We drink water from the tap, and we are told the water is recycled but we still drink it. We leave our natural things and run to the tap water knowing that it is recycled" (FGD_peri-urban).

"I am not aware of any religious or cultural barrier" (FGD_Peri-urban).

"There is nothing about the culture that prevents us from growing food from this treated wastewater" (FGD_rural area).

Indigenous Practices and Acceptability of Treated Effluent in Agriculture

"The same thing works with cow dung that is used for fertilization. It is used and as more as things are being exposed to us that these things can work, we need to learn that these things can help us with our farm"

(FGD_rural area).

Barriers to the use of treated effluent in agriculture
"I will use it if it does not make me sick" (FGD_peri-urban).

"I am afraid that when I am using it to water the garden, I can get sick by touching it" (FGD_rural area).

Source: field data.

\section{Results}

\subsection{Willingness to Use Treated Sanitation Effluent in Agriculture}

One of the aims of this study was to understand if the study participants were open to using DEWATS effluent in agriculture. In all the focus group discussions, no participant was opposed to using the effluent in agriculture. This is consistent with the growing body of evidence on the acceptance of human excreta in agriculture $[4,28,33,35,60]$. Most respondents noted that it was a good idea to use effluent in agriculture, even though none was aware of its potential benefit in agriculture before the focus groups. Some participants drew parallels between water recycling in urban centers and 
using effluent in agriculture. These participants noted that since recycled water is used in urban areas, there was no reason to object to using treated effluent in agriculture.

Some of the interviewees from rural areas with experience of using greywater from laundry to irrigate farms compared this practice to the use of DEWATS effluent. These respondents were introduced to the use of greywater for irrigation by a local non-governmental organization to address water scarcity. As the study by Roxburgh et al. [38] found, prior knowledge is a determinant of acceptability of human excreta in agriculture. For these participants, their prior knowledge of recycling greywater in agriculture coupled with the challenge of water scarcity in the area contributed to their willingness to accept DEWATS effluent in agriculture.

\subsection{Willingness to Consume Food Grown with Treated Sanitation Effluent}

In addition to the acceptance of growing food with treated effluent, the study also examined the willingness of participants to consume food grown using treated effluent. Analysis of focus group discussions showed that all participants were open to consuming food cultivated using treated effluent (Table 1). Some respondents alluded to the possibility that they could already be consuming food grown using treated effluent since they do not know how the food they buy is produced.

Two other participants observed that they consume food that they knew was contaminated with harmful chemicals, such as Dichlorodiphenyltrichloroethane. These participants noted that consuming food grown with treated effluent is not considered a problem, since it does not contain harmful chemicals. Another participant raised a similar view, noting that effluent is a natural resource that should be reused in agriculture.

\subsection{Indigenous Practices and Acceptability of Treated Effluent in Agriculture}

Studies that have examined the social acceptability of human excreta in agriculture sometimes point to the notion that indigenous beliefs and cultural practices oppose close contact with human excreta $[34,36,39,61]$. These studies argue that cultural intolerance of close contact with human excreta is a key barrier to reusing human excreta in agriculture. Against this backdrop, we asked our study participants if there were cultural/religious knowledge and practices that could be barriers to using effluent in agriculture. The findings of this study showed that all participants were of the view that there was nothing in their culture/religion that forbids using effluent in agriculture.

One participant compared human excreta to cow manure. According to the interviewee, it is a traditional practice to use cow dung as manure. The participant further pointed out that farmers need to be open to new farming practices that can improve yields.

The traditional practice of harvesting and consuming vegetables from spots around the homestead where young men dispose of urine from the household is another practice that was used to justify acceptance of reusing human excreta in agriculture. According to a participant, this part of the homestead is "usually the very fertile area around the house. We get imbuya [amaranth] from there to cook". The participant observed that this practice shows that cultural practices were not opposed to reusing human excreta in agriculture. According to the participant, the fact that people knew that the amaranth they harvested flourished because of urine but still consume it is an indication that they are tolerant of reusing human excreta in agriculture.

Just like the above view, another participant cited the practice of open defecation and the growing and consumption of food from the same spot as a justification for the acceptance of the DEWATS effluent in agriculture. The participant noted that communities are aware that human excreta in such a location become manure that enhances plant growth. For the participant, such a practice demonstrates that traditional society was not opposed to using human excreta in agriculture. The above demonstrates the value of indigenous knowledge in addressing societal issues, such as agriculture [51,52] and climate change [43,53-55]. 


\subsection{Barriers to the Use of Treated Effluent in Agriculture}

One of the goals of this study was to understand possible barriers to the adoption of effluent in agriculture. Although participants in the focus groups were of the view that there was nothing in their indigenous beliefs or cultural practices that forbade using treated effluent in agriculture, there were observations about possible associated health risks. Several participants were concerned about becoming ill from contact with effluent in the process of irrigating their farms or due to the food being contaminated. This is consistent with other studies $[33,36,40]$ that have found health concerns as a barrier to the acceptance of using human excreta in agriculture. Despite this concern, all respondents were open to using effluent in agriculture if there is a guarantee that there are no associated health risks.

\section{Conclusions}

The primary aim of this paper was to examine whether there are indigenous knowledge and practices that enable/hinder the social acceptability of reusing effluent in agriculture. In doing this, we provided an overview of global sanitation and demonstrated its linkage to food security. The literature on the social acceptability of human excreta in agriculture showed negative attitudes toward it. Barriers such as religion, culture, smell, health, and lack of knowledge were among factors that affect social acceptance of human excreta as a resource in agriculture. In linking these barriers to the present study, it was noted that using effluent was acceptable to all study participants across both rural and peri-urban settings.

All respondents noted that it was a good idea to use treated effluent in agriculture even though they were unaware of the potential benefit of effluent in agriculture before the FGDs. The high level of acceptability of treated effluent as an agricultural resource among the study participants could be attributed to two factors. Firstly, the treated effluent in the low-cost sanitation scheme presented in this study undergoes a treatment process that makes the end product more appealing compared to the handling of raw wet or dry faecal matter and urine. In addition, the detailed explanation of the DEWATS concept gave participants a clear understanding of how the system works, thus clarifying their doubts and concerns. Given the high level of acceptability of effluent in agriculture among the study participants, it can be concluded that this provides a viable option in simultaneously addressing the challenges of sanitation backlog, the impact of climate change on reduced water availability, and food insecurity. This will entail that the design of social housing, as well as sanitation facilities, needs to consider how effluent can be harvested for agricultural use. In conclusion, we recommend additional studies to map and document further existing indigenous beliefs, practices, and perceptions of rural, peri-urban, and urban dwellers that could enhance/undermine the acceptance of using treated effluent in agriculture. Future research should examine the policy implications and institutional arrangements for the safe reuse of treated effluent in agriculture in South Africa and beyond.

Author Contributions: A.O.O. and A.E.O. conceptualized the study. A.E.O. and developed the study prootocal. A.E.O. collected, analysed and wrote the first draft of the paper. A.O.O. read and revised several versions of the manuscript. All authors have read and agreed to the published version of the manuscript.

Funding: This research was funded by the Water Research Commission (grant number K5/2220). Alfred Odindo was the primary grant holder.

Acknowledgments: We thank all the participants in this study who shared their valuable experiences and perceptions with us. Special thanks to Michael Malinga for his valuable support during data collection. We thank the two anonymous reviewers for their valuable comments.

Conflicts of Interest: The authors declare no conflict of interest. 


\section{References}

1. Drangert, J.O.; Tonderski, K.; McConville, J. Extending the european Union Waste Hierarchy to Guide nutrient-effective Urban sanitation toward Global Food security-Opportunities for phosphorus recovery. Front. Sustain. Food Syst. 2018, 2, 3. [CrossRef]

2. Langergraber, G.; Masi, F. Treatment wetlands in decentralised approaches for linking sanitation to energy and food security. Water Sci. Technol. 2018, 77, 859-860. [CrossRef] [PubMed]

3. Ganesapillai, M.; Simha, P.; Gupta, K.; Jayan, M. Nutrient recovery and recycling from human urine: A circular perspective on sanitation and food security. Procedia Eng. 2016, 148, 346-353. [CrossRef]

4. Schuurman, F.J. The research paradigm—Methodology, epistemology and ontology—Explained in simple language. Third World Q. 2000, 21,7-20. [CrossRef]

5. Gensch, R. Agriculture and sanitation. Urban Agric. 2008, 20, 38-40.

6. Esrey, S.A. Towards a Recycling Society: Ecological Sanitation-Closing the Loop to Food Security-PubMed. Available online: https://pubmed.ncbi.nlm.nih.gov/11379218/ (accessed on 11 September 2020).

7. Falkenmark, M. The greatest water problem: The inability to link environmental security, water security and food security. Int. J. Water Resour. Dev. 2001, 17, 539-554. [CrossRef]

8. Odindo, A.O.; Bame, I.B.; Musazura, W.; Hughes, J.C.; Buckley, C.A. Integrating agriculture in the design of onsite, low-cost sanitation technologies in social housing schemes. Water Res. Comm. K 2018, 5, 143-163.

9. Magwaza, S.T.; Magwaza, L.S.; Odindo, A.O.; Mditshwa, A. Hydroponic technology as decentralised system for domestic wastewater treatment and vegetable production in urban agriculture: A review. Sci. Total Environ. 2020, 698, 134154. [CrossRef]

10. World Health Organization. Sanitation Safety Planning Manual for Safe Use and Disposal of Wastewater, Greywater and Excreta; WHO: Geneva, Switzerland, 2015.

11. World Health Organization; Ritchie, H.; Roser, M. Sanitation, Our World in Data. 2019. Available online: https://ourworldindata.org/sanitation (accessed on 11 September 2020).

12. Cheng, S.; Li, Z.; Uddin, S.M.N.; Mang, H.-P.; Zhou, X.; Zhang, J.; Zheng, L.; Zhang, L. Toilet revolution in China. J. Environ. Manag. 2018, 216, 347-356. [CrossRef]

13. United Nations Children's Fund. UNICEF-Water, Sanitation and Hygiene. 2013. Available online: https://www.unicef.org/wash/ (accessed on 11 September 2020).

14. Browne, M.; Lutendo, M. Demonstration of How Healthy Ecological Infrastructure Can Be Utilized To Secure Water for the Benefit of Society and the Green Economy Through a Programmatic Research Approach Based on Selected Landscapes. 2017. Available online: https://cwrr.ukzn.ac.za/wp-content/uploads/2020/02/Del5_ WRC-EI-Deliverable-5.pdf (accessed on 21 September 2020).

15. Bill \& Melinda Gates Foundation. Water, Sanitation \& Hygiene. 2020. Available online: https://www. gatesfoundation.org/What-We-Do/Global-Growth-and-Opportunity/Water-Sanitation-and-Hygiene (accessed on 11 September 2020).

16. Haarhoff, J.; Juuti, P.; Mäki, H. A short comparative history of wells and toilets in South Africa and Finland. J. Transdiscipl. Res. S. Afr. 2006, 2, 103-130. [CrossRef]

17. Mbatha, S.; Wilson, Z.; Buckley, C. Zulu Indigenous Practices in Water and Sanitation: Preliminary Field Research on Indigenous Practices in Water and Sanitation Conducted At Ulundi. Water Inst. S. Afr. 2008, 1, 2016.

18. STATS SA. General Household Survey 2017; STATS SA: Pretoria, South Afria, 2018.

19. Wielemaker, R.C.; Weijma, J.; Zeeman, G. Harvest to harvest: Recovering nutrients with New Sanitation systems for reuse in Urban Agriculture. Resour. Conserv. Recycl. 2018, 128, 426-437. [CrossRef]

20. Lydecker, M.; Drechsel, P. Urban agriculture and sanitation services in Accra, Ghana: The overlooked contribution. Int. J. Agric. Sustain. 2010, 8, 94-103. [CrossRef]

21. Langergraber, G.; Muellegger, E. Ecological Sanitation-A way to solve global sanitation problems? Environ. Int. 2005, 31, 433-444. [CrossRef]

22. Okem, A.E.; Xulu, S.; Tilley, E.; Buckley, C.; Roma, E. Assessing perceptions and willingness to use urine in agriculture: A case study from rural areas of eThekwini municipality, South Africa. J. Water Sanit. Hyg. Dev. 2013, 3, 582-591. [CrossRef]

23. Cordell, D.; Drangert, J.; White, B. The Story of Phosphorus: Global Food Security and Food for thought. Glob. Environ. Chang. 2009, 19, 292-305. [CrossRef] 
24. Richert, A.; Gensch, R.; Jönsson, H.; Stenström, T.-A.; Dagerskog, L. Practical Guidance on the Use of Urine in Crop Production; Stockholm Environment Institute: Stockholm, Sweden, 2010.

25. Mariwah, S.; Drangert, J.O. Community perceptions of human excreta as fertilizer in peri-urban agriculture in Ghana. Waste Manag. Res. 2011, 29, 815-822. [CrossRef] [PubMed]

26. Haq, G.; Cambridge, H. Exploiting the co-benefits of ecological sanitation. Curr. Opin. Environ. Sustain. 2012, 4, 431-435. [CrossRef]

27. Moya, B.; Sakrabani, R.; Parker, A. Realizing the Circular Economy for Sanitation: Assessing Enabling Conditions and Barriers to the Commercialization of Human Excreta Derived Fertilizer in Haiti and Kenya. Sustainability 2019, 11, 3154. [CrossRef]

28. Akhtar, R.; Afroz, R.; Masud, M.M.; Rahman, M.; Khalid, H.; Duasa, J.B. Farmers' perceptions, awareness, attitudes and adaption behaviour towards climate change. J. Asia Pac. Econ. 2018, 23, 246-262. [CrossRef]

29. Appiah-Effah, E.; Nyarko, K.B.; Adum, L.; Antwi, E.O.; Awuah, E. Perception of Peri-Urban Farmers on Fecal Sludge Compost and Its Utilization: A Case Study of Three Peri-Urban Communities in Ashanti Region of Ghana. Compost Sci. Util. 2015, 23, 267-275. [CrossRef]

30. Khalid, A. Human excreta: A resource or a taboo? Assessing the socio-cultural barriers, acceptability, and reuse of human excreta as a resource in Kakul Village District Abbottabad, Northwestern Pakistan. J. Water Sanit. Hyg. Dev. 2018, 8, 71-80. [CrossRef]

31. Hedden, S.; Cilliers, J. Parched Prospects: The emerging water crisis in South Africa. Inst. Secur. Stud. Pap. 2014, 2014, 16. [CrossRef]

32. Mudombi, S.; Montmasson-Clair, G. A Case for Water and Sanitation in South Africa's Post-Lockdown Economic Recovery Stimulus Package. 2020. Available online: https://www.tips.org.za/images/TIPS_Policy_ Brief_A_case_for_water_and_in_South_Africas_post_lockdown_stpdf.pdf (accessed on 21 September 2020).

33. Hoegh-Guldberg, O.; Jacob, D.; Taylor, M.; Bindi, M.; Brown, S.; Camilloni, I.; Diedhiou, A.; Djalante, R.; Ebi, K.L.; Engelbrecht, F.; et al. Global Warming of $1.5^{\circ} \mathrm{C}$ : An IPCC Special Report on the Impacts of Global Warming of $1.5^{\circ} \mathrm{C}$ above Pre-Industrial Levels and Related Global Greenhouse Gas Emission Pathways, in the Context of Strengthening the Global Response to the Threat of Climate Chang; World Meteorological Organization: Geneva, Switzerland, 2018.

34. Rieck, C.; von Münch, E.; Hoffmann, H. Technology Review of Urine-Diverting Dry Toilets (UDDTs) Overview of Design, Operation, Management and Costs As a Federally Owned Enterprise, We Support the German Government in Achieving Its Objectives in the Field of International Cooperation for Sustai; Deutsche Gesellschaft fuer Internationale Zusammenarbeit (GIZ) GmbH: Eschborn, Germany, 2012.

35. Roxburgh, H.; Hampshire, K.; Tilley, E.A.; Oliver, D.M.; Quilliam, R.S. Being shown samples of composted, granulated faecal sludge strongly influences acceptability of its use in peri-urban subsistence agriculture. Resour. Conserv. Recycl. 2020, 7, 1-10. [CrossRef]

36. Wilde, B.C.; Lieberherr, E.; Okem, A.E.; Six, J. Nitrified human urine as a sustainable and socially acceptable fertilizer: An analysis of consumer acceptance in Msunduzi, South Africa. Sustainability 2019, 11, 2456. [CrossRef]

37. Nimoh, F.; Ohene-Yankyera, K.; Poku, K.; Konradsen, F.; Abaidoo, R.C. Farmers's perception on excreta reuse for peri-urban agriculture in Southern Ghana. J. Dev. Agric. Econ. 2014, 6, 421-428.

38. Simha, P.; Lalander, C.; Ramanathanb, A.; Vijayalakshmic, C.; McConvillea, J.R.; Vinneråsa, B.; Ganesapillaib, M. What do consumers think about recycling human urine as fertiliser? Perceptions and attitudes of a university community in South India. Water Res. 2018, 143, 527-538. [CrossRef] [PubMed]

39. Benoit, N. Individual's Perception and the Potential of Urine as Fertiliser in eThekwini, South Africa; University of KwaZulu-Natal: Durban, South Afria, 2012.

40. Roma, E.; Philp, K.; Buckley, C.; Xulu, S.; Scott, D. User perceptions of urine diversion dehydration toilets: Experiences from a cross-sectional study in eThekwini Municipality. WATER SA 2013, 39, 305-311. [CrossRef]

41. Kaya, H.O.; Seleti, Y.N. Cultural values and African indigenous knowledge systems in climate change adaptation. J. Soc. Sci. 2016, 1, 130-136. [CrossRef]

42. Owusu-Ansah, F.E.; Mji, G. African Indigenous Knowledge and Research. Afr. J. Disabil. 2013, 2, 1-5. [CrossRef] [PubMed]

43. Kolawole, O.D. Mainstreaming Local People's Knowledge and Implications for Higher Education in the South. S. Afr. J. High. Educ. 2005, 19, 1427-1443. [CrossRef] 
44. Tharakan, J. Indigenous Knowledge Systems-A Rich Appropriate Technology Resource. Afr. J. Sci. Technol. Innov. Dev. 2015, 7, 52-57. [CrossRef]

45. Nozizwe, D.; Ncube, B.; Moyo, M. Globalization and Ndebele Indigenous Knowledge Systems in Agriculture: Challenges and Opportunities. J. Pan Afr. Stud. 2014, 6, 37.

46. Mankiw, N.G. Brief Principles of Macroeconomics, 4th ed.; Thomson: Mason, OH, USA, 2007.

47. Isaac, N. Africa: COVID 19 and the Future of Economic Integration. SSRN Electron. J. 2020. [CrossRef]

48. Kaya, H.O.; Seleti, Y.N. African indigenous knowledge systems and relevance of higher education in South Africa. Int. Educ. J. Comp. Perspect. 2014, 12, 30-44.

49. Mekoa, I. Essentialising African indigenous knowledge systems in the midst of globalization and modernity. Afr. Renaiss. 2018, 15, 11-28. [CrossRef]

50. EzeanyaEsiobu, C. Indigenous Knowledge and Education in Africa; Springer: Berlin/Heidelberg, Germany, 2019. Available online: https:/library.oapen.org/bitstream/handle/20.500.12657/23270/1006886.pdf?sequence=1 (accessed on 21 September 2020).

51. Sarkar, M. Indigenous Knowledge System of the Fishermen of Sundarbans in West Bengal and their Approaches to Health, Sanitation and Climate. Indian J. Hist. Sci. 2013, 48, 135-143.

52. Yongabi, K.A.; DeLuca, L.; Mshigeni, K.; Mwendwa, S.K.; Dudley, A.; Njuakom, F.N. Can We Exploit and Adapt Indigenous Knowledge and Ethno-Botanicals for a Healthy Living in the Face of Emerging Diseases Like Ebola in Africa. Am. J. Clin. Exp. Med. Spec. Issue Clin. Innov. Dev. Diagn. Manag. Prev. Ebola Dis. (Marbg. Fever) Hemorrhagic Fevers 2015, 3, 24-28. [CrossRef]

53. Bollig, M.; Schulte, A. Environmental Change and Pastoral Perceptions: Degradation and Indigenous Knowledge in Two African Pastoral Communities. Hum. Ecol. 1999, 27, 493-514. [CrossRef]

54. Nyong, A.; Adesina, F.; Elasha, B.O. The Value of Indigenous Knowledge in Climate Change Mitigation and Adaptation Strategies in the African Sahel. Mitig. Adapt. Strateg. Glob. Chang. 2008, 12, 787-797. [CrossRef]

55. Ajayi, O.C.; Mafongoya, P.L. Indigenous Knowledge Systems and Climate Change Management in Africa; CTA: Wageningen, The Netherlands, 2017.

56. Makondo, C.C.; Thomas, D.S. Climate Change Adaptation: Linking Indigenous Knowlegde with Western Science for Effective Adaptation. Environ. Sci. Policy 2018, 88, 83-91. [CrossRef]

57. Tilley, S. The role of critical qualitative research in educational contexts: A Canadian perspective. Educ. Rev 2019, 35, 155-180. [CrossRef]

58. Mkabela, Q. Using the Afrocentric Method in Researching Indigenous African Culture. Qual. Rep. 2005, 10, 178-189.

59. Statistics South Africa. Community Survey 2016 Agricultural Households; Statistics South Africa: Pretoria, South Africa, 2016.

60. Nirit, B.-A. Gendering Agriculture. 2014. Available online: https://www.un.org/africarenewal/magazine/ special-edition-agriculture-2014/gendering-agriculture (accessed on 21 September 2020).

61. Raschid-Sally, L.; Jayakody, P. Drivers and Characteristics of Wastewater Agriculture in Developing Countries: Results from a Global Assessment; IWMI: Colombo, Sri Lanka, 2008.

Publisher's Note: MDPI stays neutral with regard to jurisdictional claims in published maps and institutional affiliations.

(C) 2020 by the authors. Licensee MDPI, Basel, Switzerland. This article is an open access article distributed under the terms and conditions of the Creative Commons Attribution (CC BY) license (http://creativecommons.org/licenses/by/4.0/). 